\title{
Estudos sobre o Movimento da Reforma Sanitária Brasileira: olhares diversos sobre um mesmo fenômeno
}

\author{
Studies about the Brazilian Health Reform Movement: different \\ perspectives on the same phenomenon
}

João Henrique Araujo Virgens', Carmen Fontes Teixeira²

DOI: $10.1590 / 0103-1104202213215$

\begin{abstract}
RESUMO A Reforma Sanitária Brasileira tem sido estudada com apoio de diferentes referenciais teórico-metodológicos, e essa variedade de abordagens motivou esta pesquisa. Portanto, o objetivo deste artigo foi analisar estudos sobre o movimento sanitário, publicados entre 1987 e 2019, a partir de uma revisão sistemática de 28 artigos selecionados, entre 426 capturados, no 'Portal de periódicos da Capes', na 'SciELO' e na ‘Biblioteca Virtual em Saúde'. Os resultados apontam que a maioria dos autores são sujeitos engajados ética e politicamente no movimento e utilizam, em grande medida, a abordagem marxista. Em relação às fontes de informação, foram priorizadas a pesquisa bibliográfica e a consulta a documentos institucionais ou publicizados pelas entidades da Reforma Sanitária Brasileira. Poucos estudos, entretanto, explicitaram claramente as estratégias metodológicas e o embasamento teórico utilizado para realizar a análise textual. Conclui-se que a escolha dos referenciais teórico-metodológicos está relacionada com a trajetória profissional e política dos autores, impactando diretamente na delimitação dos objetos de estudo e, consequentemente, no alcance e nos resultados das análises sobre o movimento sanitário.
\end{abstract}

PALAVRAS-CHAVE Ativismo político. Reforma do setor saúde. Atividade política. Movimento sanitário. Análise política em saúde.

1 Universidade Federal da Bahia (UFBA), Instituto de Saúde Coletiva (ISC) Salvador (BA), Brasil. jhenrique.av@gmail.com

2 Universidade Federal da Bahia (UFBA), Instituto de Humanidades, Artes e Ciências Professor Milton Santos (IHAC) - Salvador (BA), Brasil.

ABSTRACT The Brazilian Health Sector Reform has been approached from different theoretical and methodological perspectives, and that variety of approaches is what motivated this research. Thus, the aim of this article is to analyze studies about the Health Reform Movement, published between 1987 and 2019, from a systematic review of 28 selected articles, among the 426 collected on the 'Capes Periodicals Portal', 'SciELO', and 'Virtual Health Library'. The results indicate that the majority of authors are subjects ethically and politically engaged in the movement and largely use the Marxist approach. Concerning information sources, bibliographic research and consultation of institutional documents or documents published by Health Sector Reform entities were prioritized. However, few studies clearly explain the methodological strategies and the theoretical basis used to perform a textual analysis. It is concluded that the choice of the theoretical and methodological references is related to the professional and political trajectory of the authors, directly impacting on the delimitation of the objects of study and, consequently, on the scope and results of the analyses on the Health Reform Movement.

KEYWORDS Political activism. Health care reform. Activity, political. Health reform movement. Political analysis in health. 


\section{Introdução}

A Reforma Sanitária Brasileira (RSB) tem sido objeto de estudo de vários pesquisadores, inclusive com alguns trabalhos que têm como objetivo explicitar sua teoria e contribuir com a análise dos sujeitos envolvidos e de sua ação $0^{\mathbf{1 - 4}}$. Apesar da ampla e diversificada produção sobre o tema, continua a ser relevante o desenvolvimento de pesquisas que se proponham a revisar e atualizar as análises sobre esse fenômeno, introduzindo novos olhares, perguntas e objetivos. Ademais, cabe considerar que, na prática científica, é importante examinar, também, como esses conhecimentos têm sido construídos.

Ao analisar os estudos sobre o movimento sanitário, observam-se divergências nas interpretações acerca dos sujeitos que fazem parte dele e das estratégias que foram adotadas. Consideramos, assim, a hipótese de que essas diferenças podem decorrer não apenas do recorte dos estudos, mas também dos referenciais adotados para construir a análise. $\mathrm{Ou}$ seja, diferentes teorias e metodologias poderiam impactar na interpretação dos resultados e na própria concepção de movimento.

Diante dessa hipótese, resolvemos nos debruçar sobre os artigos publicados acerca do 'movimento da RSB' (MRSB) e examinar como esses estudos têm sido desenvolvidos. Esse enfoque é o diferencial deste artigo, já que é direcionada atenção prioritária para analisar a maneira como os autores têm estudado o 'movimento sanitário'. Ou seja, além de identificar elementos mais prevalentes e lacunas nos estudos, busca-se problematizar as diferenças observadas que podem ser resultado das escolhas teórico-metodológicas.

Nesse sentido, este trabalho tem como objetivo analisar aspectos relacionados com o modo de produção de conhecimentos sobre o MRSB (os atores políticos), com atenção especial para os sujeitos que publicam e para os referenciais teórico-metodológicos adotados em um conjunto de artigos que tratam do tema. As perguntas da pesquisa são: qual o perfil dos autores que escrevem sobre o MRSB? Onde publicam seus trabalhos? Quais teorias e métodos são acionados nesses artigos?

\section{Elementos teórico-metodológicos}

Este estudo consiste em uma revisão sistemática da literatura ${ }^{5-8}$, tendo como base uma pesquisa realizada no 'Portal de periódicos da Capes', 'SciELO' e 'Biblioteca Virtual em Saúde', utilizando separadamente as expressões "movimento sanitário", "movimento de/a reforma sanitária" e "reforma sanitária brasileira”. Adotou-se como critério de inclusão: artigos publicados em periódicos revisados por pares até o ano de 2019, tendo sido identificada, em 1987, a primeira publicação com base nesses critérios. Dos 826 artigos localizados, foram excluídos os repetidos (400), e lidos os resumos dos demais (426), sendo que, em alguns casos (89), foram lidos também a introdução e o método devido à ausência de informações claras no resumo, indicando se era realizada análise do(s) sujeito(s) da RSB. Foram descartados (398) estudos que enfocavam temáticas específicas e que apenas citaram o MRSB sem desenvolver análises sobre ele.

Os 28 artigos selecionados foram lidos na íntegra, e extraídas informações 9 para construir uma matriz de análise com os seguintes aspectos: a) momento da publicação do artigo e período analisado; b) perfil dos autores (formação acadêmica, atuação profissional e vinculação política com o movimento sanitário) com base nos registros na Plataforma Lattes; c) revistas em que os artigos foram publicados; d) referenciais teóricos utilizados; e) métodos e técnicas de produção e análise de dados.

Para melhor delimitar os aspectos relacionados com a maneira como foram desenvolvidos os estudos sobre o MRSB, adotamos como referencial uma adaptação da proposta apresentada por Bruyne et al. ${ }^{10}$ (figura 1). Nessa abordagem, a dimensão teórica é tratada como aquela que ajuda a definir a melhor lente 
para olhar, analisar e compreender o objeto do estudo, sendo a articulação conceitual desenvolvida pelo autor ou fundamentada em uma ou mais referências. A dimensão metodológica, apesar de estar diretamente conectada com a teoria, tem relação específica com a prática e com as técnicas utilizadas para selecionar as fontes, produzir dados, analisá-los e apresentar os resultados. A dimensão epistemológica envolve a preocupação com o modo de produção de conhecimentos e com o exercício constante da dúvida sobre aquilo que se apresenta como 'certeza' ou 'verdade', inclusive o que muitos pesquisadores assimilam sem problematizações, como algumas escolhas metodológicas e teóricas. É essa reflexividade ${ }^{11}$ que favorece a dimensão da crítica e ajuda a superar incoerências entre os polos e os objetivos da pesquisa. Ademais, na interconexão entre essas dimensões, a epistemologia é parte do desenvolvimento teórico e metodológico, há teoria na epistemologia e na fundamentação metodológica e há 'método' para a 'prática' epistemológica e teórica.

Figura 1. Polos de investigação

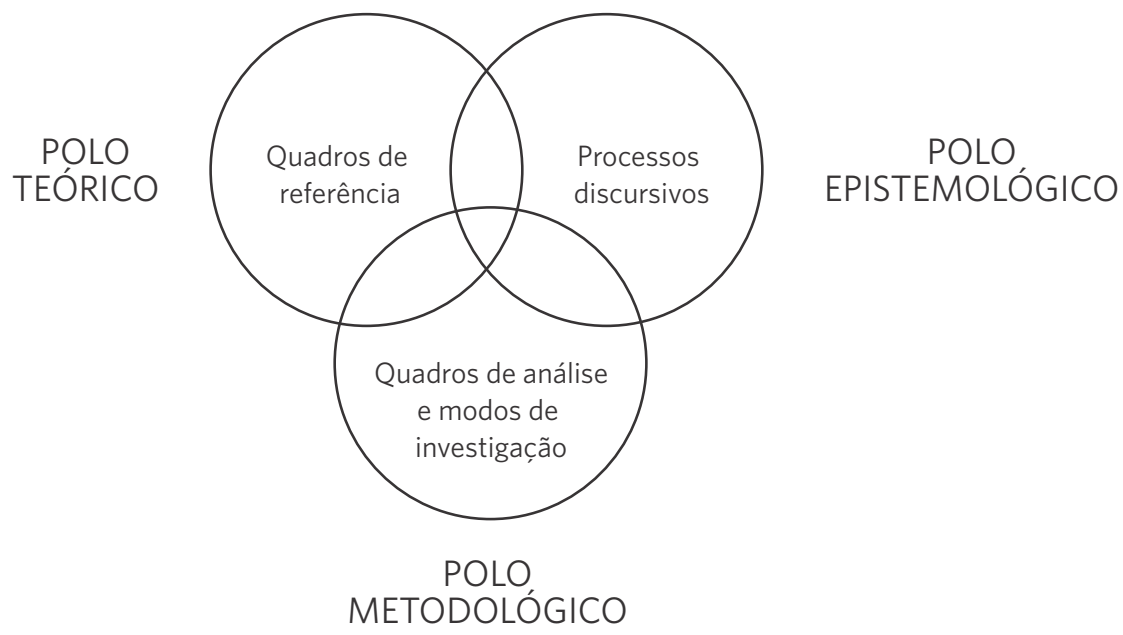

Fonte: elaboração própria com base no quadro de Bruyne et al.10.

Além de analisar o produto da pesquisa, é importante evidenciar também quem se interessa pelo tema e em qual momento histórico se dá esse interesse, considerando que a pesquisa é uma prática social12,13. É importante ter claro que as abordagens teórico-metodológicas e a escolha de temáticas podem estar imersas em disputas epistemológicas que, em alguns casos, estão relacionadas com as implicações ${ }^{14-20} \mathrm{de}$ quem realiza a pesquisa. Esses aspectos são evidenciados, por exemplo, nos necessários questionamentos acerca da viabilidade de aplicar, sem problematizações, referenciais do 'norte' para analisar a realidade latino-americana, bem como nos conflitos referentes à escolha entre adotar teorias que partem de aspectos macroestruturais ou aquelas focadas nas microrrelações sociais.

No caso desta revisão, não há como ignorar a particularidade de que muitos autores dos artigos revisados também atuam no MRSB. Isso demandou a busca por referências que examinam essa relação entre ser pesquisador e, ao mesmo tempo, 'ator político'14-20. 
Assim, nosso olhar direciona-se tanto para o 'sujeito da pesquisa' quanto para seu 'produto' (artigo publicado). Ou seja, inicialmente, dedicamos atenção para analisar o momento da publicação e sua relação com o período analisado, bem como identificar elementos relacionados com perfil político e vinculação institucional dos autores. Sobre o produto, além de considerar aspectos ligados à 'divulgação' (revistas em que foram publicados), tratamos das temáticas, das abordagens teóricas e das metodologias adotadas.

Especificamente, sobre as abordagens teórico-metodológicas, recorremos a trabalhos que evidenciam os principais referenciais utilizados em estudos das políticas de saúde e do processo político em saúde $\mathbf{1 2 , 1 3 , 2 1}^{\text {. As cor- }}$ rentes teóricas identificadas por esses autores são: marxista; institucionalismo histórico e neoinstitucionalismo; ciclo de políticas públicas; sociologia reflexiva e sociogênese das políticas; abordagens latino-americanas voltadas para análise política em saúde (a exemplo do pensamento estratégico e da planificação situacional); e as vertentes habermasiana e foucaultiana. A partir dessa sistematização, analisaremos se os estudos sobre o movimento sanitário recorrem aos mesmos referenciais e se trazem abordagens diferentes das citadas.

\section{Resultados e discussão}

\section{Periodização dos artigos}

A apresentação dos resultados toma como ponto de partida uma contextualização que evidencia tanto o momento em que os artigos foram escritos quanto o período analisado pelos autores.

Os quatro primeiros artigos produzidos sobre o movimento sanitário foram publicados no final dos anos 1980 22-25. Eles consideram fatos iniciados na década anterior à publicação, mas suas análises seguem até momentos muito próximos da conclusão da escrita. $\mathrm{Ou}$ seja, incluem análises 'no calor dos acontecimentos'. Essa abordagem se relaciona com a perspectiva identificada na análise de conjuntura ${ }^{26}$ ao estudar um 'período recente' (o 'quase-presente'), considerando fatos e atores envolvidos.

Na década de 1990, foram publicados apenas os artigos de Pereira ${ }^{27}$ e de Borba ${ }^{28}$. Ao contrário dos anteriores, eles não avançam em análises sobre períodos próximos à publicação e, por isso, assumem características de estudos históricos, tratando de um passado mais distante.

Dessa maneira, os seis primeiros artigos sobre o tema analisam o mesmo período, mas foram produzidos em contextos políticos distintos: os quatro primeiros foram escritos sob influência direta da ampla mobilização democrática, inclusive setorial, das repercussões da VIII Conferência Nacional de Saúde e da luta pela constitucionalização do Sistema Único de Saúde (SUS), enquanto os demais foram produzidos em um momento de avanço das políticas neoliberais e de luta pela institucionalização do SUS.

Após esse período, há um hiato de quase 10 anos sem produções sobre o movimento sanitário, condição que pode ser reflexo tanto da conjuntura política mais ampla como das dinâmicas setoriais. Para Fleury4(9), esse é um momento em que ocorreu um processo de "superespecialização e fragmentação da produção da saúde coletiva"; e na área de política, planejamento e gestão, o foco direcionou-se para estudos sobre políticas específicas, instituições e práticas de saúde 29,30 .

Entre 2007 e 2009, o tema é retomado com as publicações de $\mathrm{Campos}^{31}$, $\mathrm{Cohn}^{32}$, Paim ${ }^{33-35}$ e Fleury ${ }^{36}$. Em comum entre esses seis artigos, está o fato de eles realizarem atualizações das análises sobre o MRSB. Nessa década, há destaque para um momento em que um partido considerado de esquerda vence as eleições presidenciais e são explicitados os dilemas entre apoiar o governo ou aprofundar críticas. É em meados dessa década que se dá a refundação do Centro Brasileiro de Estudos 
de Saúde (Cebes) e a constituição do Fórum da Reforma Sanitária Brasileira (FRSB). Assim, aspectos conjunturais podem ter influenciado a atuação do MRSB, de maneira que ambas as variáveis (momento conjuntural e ação dos sujeitos) teriam contribuído para a retomada do interesse e das publicações sobre o tema.
A partir desse período, passa a ocorrer um aumento no número de artigos produzidos (gráfico 1), situação que confirma a tendência de ampliação das publicações na área da saúde coletiva que direcionam atenção a processos políticos, evidenciada por Santos et al. ${ }^{30}$.

Gráfico 1. Distribuição temporal dos artigos sobre o MRSB

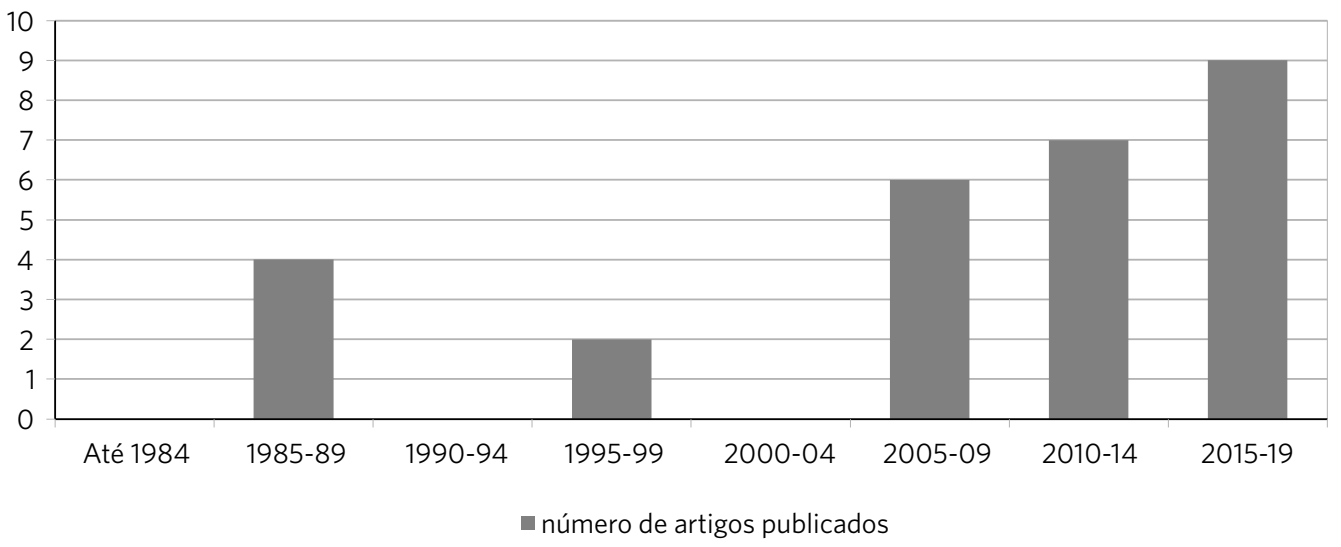

Fonte: elaboração própria22-25,27,28,31-52

As publicações seguintes (2010-2012) são de Menicucci et al. ${ }^{37}$, Falleti38 e Sophia ${ }^{39}$. Esses três artigos voltam a desenvolver análises sobre o passado.

Os artigos de Santos ${ }^{40}$ e Silva ${ }^{41}$, publicados, respectivamente, em 2013 e 2014, têm em comum o fato de as autoras serem graduadas em serviço social e analisarem a Frente Nacional Contra a Privatização da Saúde (FNCPS), de maneira a considerá-la como defensora do projeto original da RSB. Nesse caso, o surgimento dessa organização e as ações desencadeadas por ela parecem ter sido o estímulo central para a realização desses trabalhos. Chama atenção também o fato de uma das principais 'lideranças' da FNCPS (Maria Inês Bravo), que é citada em ambos os artigos, ter graduação na mesma área das autoras, evidenciando possíveis influências das interações profissionais e acadêmicas no interesse de pesquisa.

Nos estudos de Paiva et al. ${ }^{42}$, Costa ${ }^{43}$ e Jacobina $^{44}$ (2014-2016), merece atenção o fato de todos os autores serem graduados em história e examinarem acontecimentos das décadas de 1970 e 1980.

Esse é o período (2010-2016) que apresenta mais publicações dedicadas a analisar fatos do passado e que delimita exatamente o momento entre a eleição da primeira mulher à presidência e seu impedimento. São anos marcados pelas consequências da crise mundial de 2008, pelas manifestações de junho de 2013 e pela ascensão do tema da corrupção nos debates políticos. 
A partir desse momento, os artigos parecem sofrer influência direta de uma conjuntura que os próprios autores consideram como de graves retrocessos sociais e de ameaças mais sérias para o projeto da Reforma Sanitária em decorrência de medidas como a Emenda Constitucional 95 e a reforma trabalhista. Além delas, ocorreram ainda reformas específicas no setor saúde, tais como as mudanças referentes ao repasse de recursos federais ('SUS Legal') e na Política Nacional de Atenção Básica, que, em conjunto, trazem novos riscos para a construção de um sistema de saúde universal, da maneira como tem sido concebido pelo movimento sanitário.

As produções de Santos et al. ${ }^{45}$, Souto et al. 46 e Cohn ${ }^{47}$ (2016-2018) incluem considerações sobre 'fatos recentes', enquanto a de Pires-Alves et al. ${ }^{48}$ (2018) assume abordagem do passado.

Por fim, merece destaque o fato de os últimos quatro artigos, publicados em $2018 \mathrm{e}$ 2019, terem em comum a crítica relacionada com os dilemas da frágil articulação do MRSB com o movimento sindical. Stoz ${ }^{49}$ faz uma análise histórica, enquanto Dantas ${ }^{50}$, Lacaz et al..$^{51}$ e Santos ${ }^{52}$ realizam seus estudos com citações de fatos recentes, propondo, inclusive, 'perspectivas' de luta e 'tarefas' para o movimento sanitário.

\section{Quem se interessa em estudar o MRSB e onde publica}

Identificar informações que ajudem a explicitar o perfil dos autores, bem como das revistas em que foram publicados os artigos, ajuda a analisar se existem correlações entre essas dimensões e quais características de formação e área de atuação são mais prevalentes entre aqueles que se interessam por um determinado tema. Além disso, é possível identificar se há relação entre a produção científica e a ação política.

Cabe a ressalva inicial de que, ao analisar a área de formação, consideramos o número de autores (22), já que três pessoas publicaram três artigos: Cohn (socióloga), Fleury (psicóloga) e Paim (médico-sanitarista).

No caso específico da graduação, a maioria dos autores tem formação em ciências humanas: história (4), psicologia (1) e sociologia (5). Contudo, é a medicina (7) a formação do maior número de pesquisadores. Além dela, aparece apenas mais uma autora das ciências da saúde (enfermagem). Da área de ciências sociais aplicadas, aparecem as formações em serviço social (2), administração (1) e jornalismo (1).

Ao considerar também a pós-graduação, prevalece o perfil interdisciplinar (11). Situação similar ocorre ao considerar a área de atuação autodeclarada, já que 10 pesquisadores indicam atuar em mais de uma área. Merece destaque o fato de que 16 autores realizaram formação (graduada ou pós-graduada) ou atuam na área da saúde, perfazendo um total de 19 artigos escritos por pessoas que apresentam vínculos acadêmicos com essa área.

Naquilo que se refere ao veículo de publicação, a maioria dos artigos está disponível em revistas da área de ciências da saúde (17), com destaque para a 'Saúde em Debate' (10), a 'Ciência e Saúde Coletiva' (3) e a 'Physis' (2). Além desses, 5 artigos foram publicados em revistas de ciências sociais aplicadas, 3 deles na 'Katálysis'; outros 3, em revistas de ciências humanas, sendo 2 na 'Estudos de Sociologia'; e 3 em revistas descritas pelos editores como interdisciplinares. A produção, portanto, está concentrada em 13 revistas. 
Tabela 1. Áreas de conhecimento autor/revista

\begin{tabular}{lrrrr}
\hline & & $\begin{array}{r}\text { Pós-graduação em } \\
\text { relação à área de } \\
\text { graduação }\end{array}$ & $\begin{array}{r}\text { Área de atuação } \\
\text { sugerida pelo autor }\end{array}$ & Área das revistas \\
\hline Ciências humanas & 10 & 4 & 5 & $3(2)$ \\
Ciências da saúde & 8 & 5 & 6 & $17(5)$ \\
Ciências sociais aplicadas & 4 & 2 & 1 & $5(3)$ \\
Interdisciplinar & 0 & 11 & 22 autores & 3 \\
TOTAL & 22 autores & 22 autores & artigos \\
& & & & (13) revistas \\
\hline
\end{tabular}

Fonte: elaboração própria22-25,27,28,31-52

Na relação entre essas duas dimensões, cabe comentar que sete autores de outras áreas de formação optaram por publicar seus artigos em revistas de ciências da saúde. Na situação inversa, nenhum autor com formação estritamente na área da saúde publicou as produções analisadas em revistas de outras áreas. Apenas um autor com graduação na área da saúde publicou seu artigo em revista da área de ciências humanas, mas ele cursou mestrado e doutorado na área de humanas.

Ao tratar da relação entre produção científica e atuação política, merece destaque o fato de, pelo menos, 16 artigos terem sido produzidos por autores que já tinham atuação ou passaram a atuar em alguma entidade considerada como parte do 'movimento sanitário'. É importante citar também que 14 desses artigos analisaram períodos próximos em relação ao momento que foram publicados, condição que reforça a hipótese de que o interesse em estudar o desenrolar dos acontecimentos para contribuir com a ação pode ampliar-se a depender das dinâmicas conjunturais e da implicação política dos sujeitos.

Em relação às revistas, essa correlação política também pode ser considerada. Afinal, 13 trabalhos (46\% dos artigos revisados) foram publicados em periódicos editados por entidades vinculadas ao movimento sanitário ('Saúde em Debate' - Cebes e 'Ciência e Saúde Coletiva' - Associação Brasileira de Saúde Coletiva/Abrasco). Ou seja, além da ação do ator/autor, essas revistas, geridas por duas das principais entidades que integram o MRSB, tornaram-se espaços privilegiados para difundir essas produções. Caberia questionar, inclusive, se há algum motivo em comum para isso, já que, apesar de existirem outras revistas na área da saúde coletiva (tais como 'Revista de Saúde Pública'; 'Cadernos de Saúde Pública'; 'Interface - Comunicação, Saúde, Educação'; 'Cadernos Saúde Coletiva'; 'Saúde e Sociedade'), essas duas continuam a ser priorizadas pelos autores para publicações sobre esse tema. Alguns critérios como o escopo das revistas, o 'Qualis Capes', o limite de palavras/caracteres e a necessidade de pagar taxas para publicação poderiam ter influenciado diretamente a escolha pelo local de submissão. Contudo, ao comparar essas dimensões nas revistas citadas, não é possível encontrar um fator que poderia ser considerado como conclusivo para torná-las inacessíveis a publicações sobre o MRSB. Por isso, não há como descartar a hipótese de que a trajetória das instituições que são responsáveis pelas revistas seja um fator central para a decisão de priorizá-las ao submeter artigos sobre essa temática. Além disso, ao considerar que muitos artigos se propõem a realizar análises com características de estudos conjunturais, alguns deles trazendo, inclusive, sugestões a respeito das estratégias a serem adotadas pelo movimento ${ }^{50-52}$, é possível que, além do reconhecimento científico dessas revistas, 
esses autores considerem que elas tenham maior alcance entre os militantes da RSB.

Merece destaque ainda o fato de os primeiros artigos que identificamos com uso da expressão 'movimento sanitário' terem sido produzidos por autoras envolvidas com as lutas pela RSB (Fleury, Escorel e Cohn). Além disso, em um momento seguinte, após o relatado hiato de quase 10 anos sem produção de artigos que priorizassem o tema, ele volta a reaparecer entre 2007 e 2009, em publicações também escritas por pessoas envolvidas com o MRSB (Campos, Cohn, Fleury e Paim). Dessa maneira, é importante considerar o papel desses 'primeiros' atores-autores na difusão desse tema nos meios científicos.

Essa característica da produção sobre a RSB já foi apontada por Buss ${ }^{53(14)}$ na apresentação do livro 'Reforma sanitária: em busca de uma teoria', ao comentar que o grupo de pesquisa responsável pela sua produção

ao tempo em que [...] realiza o trabalho de investigação, investe também no plano político, atuando junto a entidades governamentais, científicas e da sociedade civil.

Schraiber ${ }^{19(35)}$ exemplifica essa situação, denominada por ela de "engajamento ético-político", a partir de um trabalho desenvolvido por Paim ${ }^{3}$, que se coloca como autor e ator do MRSB. Já Merhy ${ }^{15}$, ao comentar sobre pesquisas na área da saúde, analisa o 'sujeito interessado' que almeja tornar-se 'epistêmico'. Além disso, pesquisadores de outras áreas, como Vianna ${ }^{14}$, Macedo ${ }^{16,17}$, Burawoy ${ }^{18}$ e Perlatto e Sousa ${ }^{20}$, também contribuem para aprofundar a análise dos atores sociais que se colocam como autores no âmbito da produção acadêmica.

Como se observa, diversas abordagens teórico-metodológicas assumem a relação ator-autor como uma dimensão relevante, reforçando a visão de que essa implicação não é um fator impeditivo para realizar um trabalho científico. Afinal, a qualidade de qualquer produção depende, especialmente, do rigor como são tratados os aspectos teóricos, metodológicos e epistemológicos.

\section{Referenciais teóricos explicitados nos estudos}

As principais correntes que aparecem nos estudos revisados coincidem com aquelas explicitadas em nossa fundamentação teórico-metodológica, à exceção da abordagem foucaultiana que não é citada nos artigos. Por outro lado, são utilizados autores não identificados na sistematização, tais como 'Boaventura de Sousa Santos'.

Outra característica é a presença de artigos que não se fundamentam apenas em uma corrente teórica e apoiam-se em contribuições de diferentes autores para desenvolver as análises. Percebem-se ainda alguns trabalhos que não se vinculam explicitamente a alguma das correntes citadas no nosso marco teórico, mas citam conceitos específicos que contribuem para examinar algum aspecto pontual. Esses fatores limitam as tentativas de 'classificar' artigos em categorias teóricas específicas, mas, por outro lado, evidenciam a existência de diversas possibilidades de análise que podem ser utilizadas e construídas para estudar um mesmo tema de pesquisa. 
Tabela 2. Matrizes teóricas presentes nos estudos sobre o movimento da RSB

\begin{tabular}{lr}
\hline Referenciais teóricos / conceitos & Artigos \\
\hline Marxista (citam referenciais e categorias) & $28 ; 31 ; 33 ; 34 ; 35 ; 36 ; 50 ; 51 ; 52$ \\
Neoinstitucionalismo + paradigmas interacionistas & 37 \\
Neoinstitucionalismo + referencial habermasiano + ciclo de políticas públicas + & 43 \\
comunidade epistêmica & 46 \\
Ciclo de políticas públicas + comunidade epistêmica & 44 \\
Conceitos desenvolvidos por Boaventura Santos & 45 \\
Conceitos marxianos + sociologia reflexiva de Bourdieu & \\
Conceitos desenvolvidos por Mario Testa (pensamento estratégico) &
\end{tabular}

Fonte: elaboração própria.

Conforme observado na tabela 2, destaca-se o referencial marxista. Além dos nove artigos que citam autores vinculados a essa corrente, em outros textos, aparecem categorias, tais como hegemonia, luta de classe ou processo de trabalho, indicando uma aproximação mais abrangente dessa abordagem nos artigos sobre o movimento sanitário. Consideramos que a influência de militantes e de estudiosos do marxismo no interior da saúde coletiva pode ter contribuído para difundir alguns de seus conceitos de tal maneira que categorias centrais dessa corrente passaram a ser utilizadas como expressões de senso comum. Esse pode ser um dos fatores para alguns estudiosos terem dispensado citações ou explanações a respeito delas.

A maioria dos artigos que adota o referencial marxista reconhece a importância de analisar, em uma perspectiva macro, ações políticas e seus impactos nas transformações estruturais da sociedade. Contudo, apesar de autores como Paim ${ }^{33-35}$ adotarem o referencial marxista, a análise, mesmo sem desconsiderar 'o processo político' no setor, voltou-se, prioritariamente, para as mudanças nas políticas de saúde; além disso, nos resultados e discussão, pouco foi comentado sobre luta de classes e preocupações ou ações voltadas, por exemplo, para a superação do capitalismo. Isso não é apresentado como uma limitação na abordagem do autor, mas uma restrição imposta pelos achados da realidade concreta. Para Paim ${ }^{33}$, a RSB, concebida "como reforma geral, tendo como horizonte a revolução do modo de vida", ainda está em curso, mas seu processo segue "confinado, até o presente, a uma reforma parcial centrada na construção do SUS". Por isso, mesmo ao evidenciar a "ousadia da Reforma Sanitária” diante da conjuntura política que se apresentava em seu início e falar sobre "as conquistas dos movimentos sociais da saúde na defesa" dela, destaca também alguns de seus limites e a importância de "fortalecer o elemento jacobino [...] e radicalizar a democracia brasileira"35(36). Apesar das contribuições e críticas do autor, merece atenção, portanto, o fato de esses artigos terem priorizado a exposição daquilo que o 'movimento sanitário' conseguiu realizar.

Algumas das categorias marxistas são também trabalhadas nos quatro últimos artigos da série histórica, que enfatizam a pouca atenção dada pelo movimento sanitário para a articulação com a classe trabalhadora, em particular, com as organizações sindicais. Stotz ${ }^{\mathbf{4 9 ( 4 8 )}}$ desenvolve seu texto a partir da "alegoria do 'fantasma da classe 
ausente" formulada por 'Arouca', assim como o faz Dantas ${ }^{50}$, que se apoia diretamente em autores como 'Marx' e 'Gramsci' e cita 'Stotz'. Lacaz ${ }^{51}$ cita autores como 'Gramsci' e 'Perry Anderson', bem como referencia 'Dantas' para comentar sobre o afastamento do MRSB "da perspectiva emancipatória de caráter socialista”. Santos ${ }^{52}$ cita 'Stotz' e 'Lacaz', além de trazer o tema do capitalismo monopolista financeiro, neoliberalismo e seus impactos nos processos de trabalho apoiado especialmente em 'David Harvey'.

Percebe-se uma afinidade teórico-metodológica entre esses últimos artigos com citações cruzadas entre os autores que, mesmo sem apresentarem-se como membros atuantes do MRSB, tentam interferir em seus propósitos e estratégias. Assim, priorizam criticar o movimento sanitário por ter se distanciado do projeto original da reforma e pela frágil aliança com os trabalhadores na construção de lutas por transformações mais amplas na sociedade. Dessa forma, diferentemente dos artigos anteriores, o foco desses volta-se prioritariamente para aquilo que o movimento sanitário deixou de fazer (ausências).

No caso dos artigos neoinstitucionalistas, a atenção é direcionada para analisar ações que teriam interferido em 'políticas específicas' do setor saúde. Entretanto, esse referencial não foi utilizado de maneira isolada - e, nos dois artigos que se apoiaram explicitamente nele, apareceram combinações com outros referenciais, conforme tabela 2 .

É importante citar que, apesar do foco no microssocial, ambos os artigos consideram a necessidade de analisar também os elementos que geram restrições às escolhas dos atores. Para Menicucci et al. ${ }^{37(371)}$, a "consideração dos aspectos ideacionais e simbólicos não desconsidera os fatores de ordem institucional e estruturais". Pereira ${ }^{27}$ também faz a ressalva de que as escolhas individuais sofrem restrições por causa de um "conjunto de regras, leis e procedimentos a partir dos quais os atores interagem". Como se observa, apesar da abordagem proposta por esses autores ser focada na ação do ator, não deixa de ser direcionada atenção para elementos estruturais.

Merece destaque também o fato de Menicucci et al. ${ }^{37(376)}$ utilizarem como base o referencial "novo-institucionalista", mas citarem autores que atribuem ao movimento sanitário um caráter "contra-hegemônico [...], tendo como horizonte o socialismo". Ou seja, trazem para seu estudo categorias que, diferentemente das escolhas teóricas das autoras, são fundamentadas em referenciais que priorizam o olhar para as macrorrelações sociais.

Ao comparar como são apresentados e aplicados na análise esses dois primeiros referenciais, marxista e neoinstitucionalista, é possível fazer duas considerações: 1) escolhas teóricas distintas podem gerar artigos com enfoques e resultados similares ou complementares; 2) artigos com referenciais muito parecidos podem trazer respostas distintas e até opostas a uma mesma questão. Essa situação reforça o papel da crítica epistemológica na busca pelo rigor científico e a importância de articular o referencial teórico com os objetivos e os demais polos da pesquisa.

Além desses referenciais, Costa ${ }^{\mathbf{4 3}}$ traz categorias desenvolvidas por autores que se debruçam sobre o ciclo de políticas públicas, a exemplo de 'John Kingdon', e a noção de 'comunidade epistêmica' extraída da obra de 'Peter Haas'. Aparece também a combinação de conceitos da 'sociologia reflexiva' de 'Pierre Bourdieu' e da teoria marxista ${ }^{\mathbf{4}}$, bem como a incorporação de conceitos extraídos da obra de 'Mario Testa'45 em suas contribuições acerca do pensamento estratégico.

Cabe mencionar ainda a utilização de um referencial não identificado em nossa revisão sobre as correntes teóricas utilizadas para análise política em saúde. No texto de Souto et al. ${ }^{\mathbf{4 6}}$, é 'Boaventura Santos' quem aparece como o principal autor de referência, em articulação com 'Hannah Arendt' e 'José Luis Fiori'. Ou seja, surge uma abordagem que não pode ser enquadrada nas categorias anteriores e que possibilita analisar o movimento sanitário e outros temas da 
saúde coletiva a partir de outra lente. Isso reforça a necessidade de realizar estudos de revisão periodicamente para identificar quais vertentes têm sido agregadas ao grupo daquelas que permitem analisar processos políticos em saúde, bem como identificar quais têm deixado de ser utilizadas. Ter clareza sobre isso permite ampliar as discussões de caráter epistemológico sobre as variações de uso de cada abordagem ao longo do tempo e sobre as contribuições que cada uma oferece para analisar temas específicos.

Os demais artigos não explicitam vinculação com as matrizes identificadas na revisão. Porém, muitos deles trazem conceitos específicos, em especial, de outros autores da saúde coletiva, que, a depender do recorte da pesquisa, podem ser pertinentes para a análise dos objetos e processos políticos definidos. Alguns exemplos de conceitos referenciados são: complexo médico-industrial de 'Hésio Cordeiro'32,43; definição dos três projetos em disputa no âmbito da saúde, entre eles, o racionalizador, o mercantilista e o da RSB ${ }^{45}$, bem como os momentos ideia-proposta-projeto-movimento-processo ${ }^{41}$, fundamentados em 'Jairnilson Silva Paim'; medicalização social, processo de trabalho e organização da prática médica referenciando 'Roberto Passos Nogueira'22,31, e o dilema preventivista de 'Antônio Sérgio Arouca'22.

A priorização em citar autores da saúde coletiva é confirmada ao analisar as referências dos trabalhos revisados. Além de Escorel (19), Fleury (19) e Paim (17), outras pessoas frequentemente citadas nos artigos são: Oliveira (10); Arouca (8); Berlinguer (8); Gerschman (8), Rodriguez Neto (8), Cordeiro (7) e Cohn (6). Dessa maneira, cabe considerar a influência dessas produções para os estudos subsequentes e merece destaque o fato de todos esses autores terem contribuído diretamente para as lutas desenvolvidas pelo MRSB, o que evidencia o papel dos autores-atores não apenas na ação política, mas também na construção de conhecimentos, na sua difusão e no estímulo para novas produções.

\section{Estratégias metodológicas adotadas}

Como tem sido observado em outras revisões sobre temas que articulam saúde e política9 a maioria dos artigos analisados não explicita aspectos relacionados com a metodologia.

Os trabalhos revisados utilizam como fonte de dados, principalmente, publicações científicas e outros textos. Entre as fontes explicitadas, destaca-se a revista 'Saúde em Debate' $\mathbf{3 3 , 3 9 , 4 4 , 4 5 , 5 1}$. São utilizados também materiais produzidos pela Comissão Nacional de Reforma Sanitária e pelo Departamento Intersindical de Estudos e Pesquisas de Saúde e dos Ambientes de Trabalho ${ }^{51}$; jornais, publicações da 'Radis', documentos de arquivos pessoais e entrevistas (com militantes da RSB) registradas no acervo da Fiocruz ${ }^{\mathbf{4 8}}$ e documentos publicizados pelo Cebes ${ }^{45}$.

Além dessas fontes, foi observada a realização de entrevistas ${ }^{27}$ ou a mescla dessa abordagem com análise documental25,44. Foi identificado também um artigo que articulou pesquisa bibliográfica, análise de alguns documentos políticos produzidos pela Frente Nacional Contra Privatização da Saúde e pelo Fórum da Reforma Sanitária Brasileira, além do acompanhamento e observação de algumas de suas atividades ${ }^{41}$.

No caso da escolha das fontes e do desenho de estudo, alguns autores citam referências que sugerem uma preocupação em dar sustentação teórica ao uso do método. Paim ${ }^{34(625)}$, por exemplo, afirma realizar "estudo de caso" com base em 'Robert K. Yin', argumentando que conta "com muitas das técnicas utilizadas pelas pesquisas históricas"34(630). Na mesma linha, Sophia ${ }^{39(555)}$ justifica a escolha de utilizar a revista 'Saúde em Debate' para analisar o Cebes por ser um dos principais veículos de difusão das ideias do movimento sanitário. A autora apoia-se em 'Eliana de Freitas Dutra' para afirmar que a revista poderia ser tomada como "uma produção social e cultural", transformada "em objeto da história e, dessa forma, em uma unidade de compreensão". Jacobina ${ }^{44(150)}$, por sua vez, analisa entrevistas realizadas 
"com lideranças do movimento sanitário que atuaram em sua gênese”, fundamentando-se em 'Alessandro Portelli', que discute o "uso de fontes orais em pesquisa histórica”.

Na dimensão do processo analítico, poucos são os artigos que detalham como os dados relativos à pesquisa foram examinados, mas, na maioria deles, o referencial teórico serviu de apoio para as análises. Menicucci et al. ${ }^{37}$, por exemplo, utilizam referenciais que ajudam a embasar as comparações entre a reforma sanitária e a reforma urbana, destacando as especificidades de cada processo.

Merece atenção, ainda, o fato de não terem sido identificados, em nenhum dos artigos, comentários a respeito dos métodos utilizados para escolha e construção do arcabouço teórico. A maneira como os artigos analisados apresentam os referenciais teóricos segue a lógica de uma revisão narrativa, já que não foram explicitadas evidências de que teria sido desenvolvido algum método sistemático voltado para mapear as teorias que contribuem para o tipo de análise proposta.

Um elemento comum aos artigos é o fato de que todos utilizaram processos de análise textual, o que reforça a necessidade de os autores se debruçarem sobre abordagens teórico-metodológicas referentes ao estudo de textos, de maneira a conhecer as 'teorias' desses métodos e algumas das técnicas de aplicação para ampliar as possibilidades de crítica epistemológica ao seu próprio modo de examinar as fontes de informação. A articulação entre essas dimensões, contudo, é negligenciada pelos autores revisados, e isso merece atenção para evitar que o método seja tratado como um processo que não precisa de fundamentação ou de crítica epistemológica.

\section{Comentários finais}

Como foi possível observar, elementos como os fatos conjunturais, a área de formação e o engajamento dos sujeitos podem influenciar na escolha do momento da escrita, do recorte da pesquisa e de qual período analisar.

Merece destaque a variedade de referenciais para analisar o 'movimento sanitário', e fica evidente que o referencial teórico, por si só, não é o fator que determina o alcance do estudo. Além disso, nota-se a complexidade de tentar estabelecer um enquadramento que vincule os artigos a uma determinada matriz teórica, em especial, nos casos em que essa dimensão não aparece de maneira explícita ou em que são citados autores de diferentes correntes. Alguns trabalhos apoiaram-se em uma multiplicidade de conceitos de diferentes autores, o que evidencia as diversas possibilidades de análise acerca de um mesmo fenômeno. Não é nosso propósito analisar se uma é melhor que outra, mas percebe-se complementaridades nos enfoques e nos resultados de cada uma, de modo a enriquecer o processo analítico.

Além disso, nos artigos revisados, grande parte dos pesquisadores optou por apoiar-se exclusivamente na contribuição teórica de autores 'clássicos' e 'contemporâneos' da saúde coletiva que, em certos casos, explicitam sua vinculação a alguma das abordagens teóricas citadas. Arouca ${ }^{54}$, que articula 'Foucault' com o marxismo, e Paim ${ }^{33-35}$, que explicita vinculação ao referencial gramsciano, estão entre os mais citados nos artigos sobre o movimento sanitário. Essa situação sugere que a constituição do campo da saúde coletiva ${ }^{55}$ tem gerado uma elaboração teórica suficientemente reconhecida para dar sustentação à análise política em saúde. É importante, no entanto, considerar que a saúde coletiva se interliga com referenciais que podem ser cada vez mais ocultados e silenciados à medida que os 'clássicos' de outras áreas são abandonados para evidenciar exclusivamente as citações de autores dessa 'nova' corrente. Os elementos centrais das teorias originais seguem presentes, mas é possível chegar a situações em que nem mesmo os autores percebem mais seus próprios elos teóricos.

Por fim, compartilhamos algumas questões que surgiram diante das conclusões a 
que chegaram alguns dos autores, tendo o propósito de estimular novas reflexões e pesquisas: é possível determinar previamente se o olhar analítico para o passado e distanciado dos sujeitos é mais seguro naquilo que poderia se chamar de 'busca pela verdade' quando tratamos da cientificidade da análise política? Quais as vantagens e desvantagens de realizar uma análise conjuntural ou histórica, bem como do estudo ser desenvolvido por sujeitos engajados ou externos às organizações? É necessário escolher uma ou outra ou há mais ganhos científicos com a oportunidade de confrontá-las? Ao analisar uma organização política, suas estratégias e a correlação de forças em seu interior, é possível descobrir quantas faces ela tem? E no caso do movimento sanitário, que nem chega a se constituir como uma organização formal, quais de suas faces se mostraram visíveis para cada pessoa que o analisou? Quantas ainda seguem ocultas?

\section{Referências}

1. Teixeira SF, organizadora. Reforma sanitária: em busca de uma teoria. 2. ed. São Paulo: Cortez; Rio de Janeiro: Abrasco; 1995.

2. Escorel S. Reviravolta na saúde: origem e articulação do movimento sanitário. Rio de Janeiro: Editora Fiocruz; 1999.

3. Paim JS. Reforma Sanitária Brasileira: contribuição para a compreensão e crítica. Salvador: Edufba; Rio de Janeiro: Fiocruz; 2008.

4. Fleury S, organizadora. Teoria da Reforma Sanitária: diálogos críticos. Rio de Janeiro: Editora Fiocruz; 2018.
Essas perguntas estão interligadas, e cada pessoa que se debruçar sobre elas poderá encontrar respostas diversas a depender das suas escolhas teóricas e metodológicas. Por isso, esperamos que elas sejam recebidas como um convite para o diálogo. Afinal, consideramos que a crítica epistemológica depende dos embates dialógicos, especialmente, entre aqueles que trilharam diferentes caminhos de pesquisa.

\section{Colaboradores}

Virgens JHA (0000-0001-9119-280X)* contribuiu para concepção do estudo, aquisição e análise dos dados; elaboração de versões preliminares do artigo e aprovação da versão final do manuscrito. Teixeira CF (0000-00028080-9146)* contribuiu para revisão crítica do conteúdo e aprovação final do manuscrito
5. Lopes ALM, Fracolli LA. Revisão sistemática de literatura e metassíntese qualitativa: considerações sobre sua aplicação na pesquisa em enfermagem. Texto contexto - enferm. 2008 [acesso em 2018 maio 15]; 17(4):771-78. Disponível em: http://ref.scielo.org/4j83wh.

6. Gomes IS, Caminha IO. Guia para estudos de revisão sistemática: uma opção metodológica para as Ciências do Movimento Humano. Movimento. 2014 [acesso em 2018 maio 15]; 20(1):395-411. Disponível em: www.seer.ufrgs.br/Movimento/article/viewFile $/ 41542 / 28358$.

7. Sampaio RF, Mancini MC. Estudos de revisão siste-
* Orcid (Open Researcher and Contributor ID). 
mática: um guia para síntese criteriosa da evidência científica. Rev. Bras. Fisioter. 2007 [acesso em 2018 maio 15]; 11(1):83-89. Disponível em: http://ref.scielo.org/ $5 \mathrm{k} 52 \mathrm{v} 3$.

8. Rother ET. Revisão sistemática X revisão narrativa. Acta Paul. Enferm. 2007 [acesso em 2018 maio 15]; 20(2):v-vi. Disponível em: http://ref.scielo.org/fphy7j.

9. Bardin L. Análise de conteúdo. 4. ed. Lisboa: Edições 70; 2010.

10. Bruyne P, Herman J, Schoutheete M. Dinâmica da pesquisa em ciências sociais: os pólos da prática metodológica. Rio de Janeiro: Francisco Alves; 1977.

11. Oliveira SR, Piccinini VC. Validade e reflexividade na pesquisa qualitativa. Cad. Ebape.Br. 2009 [acesso em 2020 dez 28]; 7(1):88-98. Disponível em: https:// www.scielo.br/pdf/cebape/v7nl/v7nla07.pdf.

12. Mattos RA, Baptista TWF, organizadores. Caminhos para análise das políticas de saúde. Porto Alegre: Rede Unida; 2015.

13. Paim JS. Posfácio. Análise política em saúde: um pensamento estratégico para a ação estratégica. In: Federico L. Análise política em saúde: a contribuição do pensamento estratégico. Salvador: Edufba; 2015.

14. Vianna LW. Ator, tempo e processo de longa duração em análises de conjuntura. In: Vianna LW. De um plano Collor a outro: estudo de conjuntura. Rio de Janeiro: Revan; 1991.

15. Merhy EE. O conhecer militante do sujeito implicado: o desafio de reconhecê-lo como saber válido. In: Franco TB, Peres MAA, Foschiera MMP, et al., organizadores. Acolher Chapecó: uma experiência de mudança do modelo assistencial, com base no processo de trabalho. São Paulo: Editora Hucitec; 2004.

16. Macedo RS. A Etnopesquisa Crítica e Multirreferencial nas Ciências Humanas e na Educação. 2. ed. Salvador: EDUFBA; 2004.
17. Macedo RS. A etnopesquisa implicada: pertencimento, criação de saberes e afirmação. Brasília, DF: Liber Livro; 2012.

18. Burawoy M. O marxismo encontra Bourdieu. Campinas: Ed. Unicamp; 2010.

19. Schraiber LB. Engajamento ético-político e construção teórica na produção científica do conhecimento em saúde coletiva. In: Baptista TWF, Azevedo CS, Machado CV. Políticas, planejamento e gestão em saúde: abordagens e métodos de pesquisa. Rio de Janeiro: Editora Fiocruz; 2015.

20. Perlatto F, Sousa DT. Interpretações do Brasil contemporâneo: cientistas sociais, conjuntura política e a democracia brasileira. In: Anais do $40^{\circ}$ Encontro Anual da ANPOCS, 2016 out 24-27, Caxambu. Caxambu: Associação Nacional de Pós-Graduação e Pesquisa em Ciências Sociais; 2016. [acesso em 2018 jun 6]. Disponível em: https://www.anpocs.com/index.php/ papers-40-encontro/st-10/st15-7/10291-interpretacoes-do-brasil-contemporaneo-cientistas-sociais-conjuntura-politica-e-a-democracia-brasileira/file.

21. Esperidião MA. Análise política em saúde: síntese das abordagens teórico-metodológicas. Saúde Debate. 2018 [acesso em $2018 \mathrm{dez} 12$ ]; 42 (esp2):341-60. Disponível em: http://ref.scielo.org/pn323s.

22. Teixeira SMF. O dilema reformista na reforma sanitária brasileira. Rev. Adm. Pública. 1987 [acesso em 2018 set 11]; 21(4):94-115. Disponível em: http:// bibliotecadigital.fgv.br/ojs/index.php/rap/article/ view/9610/8659.

23. Teixeira SMF. Política de saúde na transição conservadora. Saúde debate. 1989 [acesso em 2018 set 11]; (26):42-53. Disponível em: http://docvirt.com/asp/ acervo_cebes.asp?Bib=SAUDEDEBATE\&PASTA= TODOS $\&$ pesq $=\& \mathrm{x}=95 \& \mathrm{y}=9$.

24. Cohn A. Caminhos da reforma sanitária. Lua Nova. 1989 [acesso em 2020 set 20]; (19):123-140. Disponível em: https://doi.org/10.1590/S010264451989000400009. 
25. Escorel S. Saúde e democracia, democracia é saúde. Saúde debate. 1988 [acesso em 2018 set 11]; (21):515. Disponível em: http://docvirt.com/docreader.net/ SaudeDebate/184.

26. Virgens JHA. Análise política em saúde: contribuições teórico-metodológicas acerca das dinâmicas estruturais, conjunturais, dos sujeitos e das ações políticas. [tese]. Salvador: Universidade Federal da Bahia; 2019. 292 p.

27. Pereira C. A política pública como caixa de pandora: Organização de interesses, processo decisório e efeitos perversos na Reforma Sanitária Brasileira - 19851989. Dados. 1996 [acesso em 2018 set 11]; 39(3). Disponível em: http://ref.scielo.org/65pzs3.

28. Borba J. Políticas de saúde e democracia: estratégias, impasses e contradições do movimento sanitário brasileiro. Rev. Katálysis. 1998 [acesso em 2018 set 11]; 3:19-27. Disponível em: https://periodicos.ufsc.br/ index.php/katalysis/article/view/5644/5093.

29. Paim JS, Teixeira CF. Política, planejamento e gestão em saúde: balanço do estado da arte. Rev. Saúde Pública. 2006 [acesso em 2017 jun 07]; 40(esp):7378. Disponível em: http://www.scielo.br/pdf/rsp/ v40nspe/30625.

30. Santos JS, Teixeira CF. Política de saúde no Brasil: produção científica 1988-2014. Saúde debate. 2016 [acesso em 2017 jun 7]; 40(108):219-230. Disponível em: http://ref.scielo.org/33vr7r.

31. Campos GWS. O SUS entre a tradição dos Sistemas Nacionais e o modo liberal-privado para organizar o cuidado à saúde. Ciênc. Saúde Colet. 2007 [acesso em 2018 set 11]; 12(supl):1865-74. Disponível em: http://ref.scielo.org/pdy9bs.

32. Cohn A. A reforma sanitária brasileira: a vitória sobre o modelo neoliberal. Social Medicine. 2008 [acesso em 2018 set 11]; 3(2):82-94. Disponível em: http:// www.socialmedicine.info/index.php/socialmedicine/article/view/225.

33. Paim JS. 20 Anos de construção do sistema único de saúde. Tempus - Actas de Saúde Coletiva. 2008 [acesso em 2018 set 11]; 2(1):63-86. Disponível em: http:// www.tempusactas.unb.br/index.php/tempus/article/view/541/1526.

34. Paim JS. A reforma sanitária brasileira e o Sistema Único de Saúde: dialogando com hipóteses concorrentes. Physis. 2008 [acesso em 2018 set 11]; 18(4):625644. Diponível em: http://ref.scielo.org/qrt2wh.

35. Paim JS. Uma análise sobre o processo da Reforma Sanitária brasileira. Saúde debate. 2009 [acesso em 2018 set 11]; 33(81):27-37. Disponível em: https://repositorio.ufba.br/ri/bitstream/ri/5978/1/Paim\%20 JS\%202009.\%20Artigo2.pdf.

36. Fleury S. Reforma sanitária brasileira: dilemas entre o instituinte e o instituído. Ciênc. Saúde Colet. 2009 [acesso em 2018 set 11]; 14(3):743-752. Disponível em: http://ref.scielo.org/png8h3.

37. Menicucci TMG, Brasil FPD. Construção de agendas e inovações institucionais: análise comparativa da reforma sanitária e da reforma urbana. Estud. sociol. 2010 [acesso em 2018 set 11]; 15(29):369-396. Disponível em: https://periodicos.fclar.unesp.br/estudos/ article/view/2971/2713.

38. Falleti TG. Infiltrando o Estado: a evolução da reforma da saúde no Brasil, 1964-1988 Estud. sociol. 2010 [acesso em 2018 set 11]; 15(29):345-368. Disponível em: https://periodicos.fclar.unesp.br/estudos/article/view/2970.

39. Sophia DC. Notas de participação do CEBES na organização da $8^{\text {a }}$ Conferência Nacional de Saúde: o papel da Revista Saúde em Debate. Saúde debate. 2012 [acesso em 2018 set 11]; 36(95):554-561. Disponível em: http://ref.scielo.org/8qtwmt.

40. Santos MA. Lutas sociais pela saúde pública no Brasil frente aos desafios contemporâneos. Rev. Katálysis. 2013 [acesso em 2018 set 11]; 16(2):233-240. Disponível em: http://ref.scielo.org/sb48gd.

41. Silva AX. A reforma sanitária brasileira na contemporaneidade: resistência ou consenso. Rev. Katálysis. 
2014 [acesso em 2018 set 11]; 17(2):159-166. Disponível em: http://ref.scielo.org/wktpms.

42. Paiva CHA, Teixeira LA. Reforma sanitária e a criação do Sistema Único de Saúde: notas sobre contextos e autores. Hist. cienc. Saude-Manguinhos. 2014 [acesso em 2018 set 11]; 21(1):15-35. Disponível em: http://ref.scielo.org/2my6qx.

43. Costa NR. Comunidade epistêmica e a formação da reforma sanitária no Brasil. Physis. 2014 [acesso em 2018 set 11]; 24(3):809-829. Disponível em: http://ref. scielo.org/cqy9xb.

44. Jacobina AT. A relação do Cebes com o PCB na emergência do movimento sanitário. Saúde debate. 2016 [acesso em 2018 set 11]; 40(esp):148-162. Disponível em: http://ref.scielo.org/bdtrvt.

45. Santos JS, Teixeira CF. Crise, refundação do cebes e reafirmação do projeto da reforma sanitária Brasileira. Saúde debate. 2016 [acesso em 2017 jun 12]; 40(esp):136-147. Disponível em: http://ref.scielo.org/ fkw2jm.

46. Souto LRF, Oliveira MHB. Movimento da Reforma Sanitária Brasileira: um projeto civilizatório de globalização alternativa e construção de um pensamento pós-abissal. Saúde debate. 2016 [acesso em 2018 set 11]; 40(108):204-218. Disponível em: http://ref.scielo.org/z9mzk3.

47. Cohn A. "Caminhos da reforma sanitária”, revisitado. Estudos Av. 2018 [acesso em 2018 set 11]; 32(93):225241. Disponível em: https://www.scielo.br/pdf/ea/ v32n93/0103-4014-ea-32-93-0225.pdf.

48. Pires-Alves FA, Paiva CHA, Lima NT. Na Baixada Fluminense, à sombra da 'Esfinge do Rio': lutas populares e políticas de saúde na alvorada do SUS. Ciênc. Saúde Colet. 2018 [acesso em 2018 set 11]; 23(6):184958. Disponível em: http://ref.scielo.org/9nwsqb.

49. Stotz E. "O fantasma da classe ausente": ensaio sobre as bases sociais do Movimento da Reforma Sa- nitária. Em Pauta. 2019 [acesso em 2020 out 20]; 17(43):48-59. Disponível em: https://doi.org/10.12957/ rep.2019.42501.

50. Dantas AV. Saúde, luta de classes e o 'fantasma' da Reforma Sanitária Brasileira: apontamentos para sua história e crítica. Saúde debate. 2018 [acesso em 2020 out 20]; 42(esp3):145-57. Disponível em: https://doi. org/10.1590/0103-11042018s311.

51. Lacaz FAC, Reis AAC, Lourenço EÂS, et al. Movimento da Reforma Sanitária e Movimento Sindical da Saúde do Trabalhador: um desencontro indesejado. Saúde debate. 2019 [acesso em 2020 out 20]; 43(esp8):120-132, 2019. Disponível em: https://doi. org/10.1590/0103-11042019s809.

52. Santos RPO. Reforma Sanitária Brasileira e o sindicalismo na saúde: quais perspectivas no contexto atual? Saúde debate. 2019 [acesso em 2020 out 20]; 43(esp8):234-47. Disponível em: https://doi. org/10.1590/0103-11042019s817.

53. Buss PM. Apresentação. In: Teixeira SF, organizadora. Reforma sanitária: em busca de uma teoria. 2. ed. São Paulo: Cortez; Rio de Janeiro: Abrasco; 1995.

54. Arouca ASS. O dilema preventivista: contribuição para compreensão e crítica da medicina preventiva. [tese]. Campinas: Faculdade de Ciências Médicas, Universidade Estadual de Campinas; 1975. 196 p.

55. Vieira-da-Silva LM. O campo da saúde coletiva. Gênese, transformações e articulações com a Reforma Sanitária Brasileira. Rio de Janeiro; Salvador: Fiocruz; Edufba; 2018.

\footnotetext{
Recebido em 14/08/2021

Aprovado em 07/12/2021

Conflito de interesses: inexistente

Suporte financeiro: Coordenação de Aperfeiçoamento de Pessoal de Nível Superior - Brasil (Capes) - Código de Financiamento 001, por meio de concessão de bolsa para Virgens JHA, durante o período de realização do estudo
} 